\title{
Steroids. III. Alumina-Induced Reactions of Steroidal Oxime Acetates ${ }^{1)}$
}

\author{
MasayuKi Onda and KeIJI TaKeUchi \\ School of Pharmaceutical Sciences, Kitasato University ${ }^{2)}$
}

(Received November 6, 1972)

\begin{abstract}
An alumina-induced reaction of 6 -acetoximino- $3 \beta$-acetoxycholestan-5 $\alpha$-ol nitrite (I) is examined and affords several kinds of compounds. Among them II, III and IV are belong to the same type of compound. From the spectral data and their reactions, the structures containing $5 \alpha, 6 \alpha$-epoxy and $6 \beta, 7 \beta$-isonitrosoimino groups are tentatively assumed for them. V and VI are identified to be another type containing $5 \alpha$-acetoxy and 6-oxo groups. The formation pathways of both types of compounds are deduced by comparison with the reaction products of the relative compounds.
\end{abstract}

Various kinds of chemical transformations are known to occur on alumina. ${ }^{3)}$ During our studies on steroids, we found a series of interesting reactions of steroidal oxime acetates on alumina under the conditions of chromatography. We now wish to report rearrangement reactions of 6 -acetoximinocholestanes on alumina.

When allowed to remain on a column of neutral alumina (Grade III) for $48 \mathrm{hr}$ and eluted with several kinds of solvents (see Experimental), 6-acetoximino- $3 \beta$-acetoxycholestan- $5 \alpha$-ol nitrite (I) afforded compound (II), $\mathrm{C}_{29} \mathrm{H}_{46} \mathrm{O}_{4} \mathrm{~N}_{2}$, compound (III), $\mathrm{C}_{29} \mathrm{H}_{46} \mathrm{O}_{4} \mathrm{~N}_{2}$, compound (IV), $\mathrm{C}_{27} \mathrm{H}_{44} \mathrm{O}_{3} \mathrm{~N}_{2}$, compound (V), $\mathrm{C}_{31} \mathrm{H}_{50} \mathrm{O}_{5}$, and compound (VI), $\mathrm{C}_{29} \mathrm{H}_{48} \mathrm{O}_{4}$.

$\mathrm{V}$ and VI were identified as $3 \beta, 5 \alpha$-diacetoxycholestan-6-one ${ }^{1)}$ and $5 \alpha$-acetoxycholestan$3 \beta$-ol-6-one, ${ }^{1)}$ respectively, by infrared (IR) and nuclear magnetic resonance (NMR) spectral comparison, and mixed melting point.

When allowed to stand in acetic acid at room temperature, II was quantitatively converted into an $\alpha, \beta$-unsaturated aldehyde (VII), $\mathrm{C}_{29} \mathrm{H}_{46} \mathrm{O}_{3}$, whose IR spectrum showed the absorptions at $2725(\mathrm{CHO}), 1735(\mathrm{OAc}), 1680(\mathrm{CHO})$, and $1600 \mathrm{~cm}^{-1}(\mathrm{C}=\mathrm{C})$, and NMR spectrum $\left(\mathrm{CCl}_{4}\right)$ showed the signals at $\delta 9.90 \mathrm{~s}(\mathrm{CHO}), 4.67 \mathrm{~m}\left(W_{\mathrm{H}}=24,3 \alpha-\mathrm{H}\right), 3.47 \mathrm{q}(J=14$ and $4,4 \alpha-\mathrm{H}), 2.00 \mathrm{~s}(3 \beta-\mathrm{OAc})$, and $0.97 \mathrm{~s}(10 \beta-\mathrm{Me})$. 2.4-Dinitrophenylhydrazone of VII was identified with an authentic sample of 2,4-dinitrophenylhydrazone of $3 \beta$-acetoxy-6-formylB-norcholest-5-ene. ${ }^{4)}$ Catalytic reduction of II over Adams' platinum in a mixed solvent of benzene and methanol, also, afforded $3 \beta$-acetoxy-6-formyl-B-norcholest-5-ene. Both reactions, in conclusion, were resulted in losing $\mathrm{N}_{2} \mathrm{O}$ unit.

An upper part of the mass spectrum of II is recorded in Table I. The pattern of fragmentation below $m / e 382$ is the same as that of VII. This fact exhibits that the structure of II has a $\mathrm{N}_{2} \mathrm{O}$ group, which is eliminated in the fragmentation process to remain an $\alpha, \beta$-unsaturated aldehyde function in the $\mathrm{B}$ ring. The IR spectrum of II shows the absorptions at $1735(\mathrm{OAc}), 1690$ and $1600 \mathrm{~cm}^{-1}(>\mathrm{N}-\mathrm{NO})$. The NMR spectrum $\left(\mathrm{CCl}_{4}\right)$ of II shows the signals at $\delta 4.83 \mathrm{q}(J=8 \text { and } 4,7 \alpha-\mathrm{H},)^{5)} 4.57 \mathrm{~m}\left(W_{\mathrm{H}}=24,3 \alpha-\mathrm{H}\right), 3.23 \mathrm{q}(J=16$ and $4,4 \alpha-\mathrm{H})$, $2.00 \mathrm{~s}(3 \beta-\mathrm{OAc})$, and $1.00 \mathrm{~s}(10 \beta-\mathrm{Me})$. From these spectral data, the structure shown in Chart 1 , i.e., $3 \beta$-acetoxy- $5 \alpha, 6 \alpha$-epoxy- $6 \beta, 7 \beta$-isonitrosoiminocholestane, is tentatively assumed for II.

1) Part II: M. Onda and A. Azuma, Chem. Pharm. Bull. (Tokyo), 20, 1467 (1972).

2) Location: Minato-ku, Tokyo, 108, Japan.

3) U.S. Joshi, N.P. Damadaran, and S. Dev, Tetrahedron, 24, 5817 (1968) and references cited therein.

4) K. Tanabe, R. Hayashi, and R. Takasaki, Chem. Pharm. Bull. (Tokyo), 9, 1 (1961); J.W. Cornforth, G.D. Hunter, and G. Popjak, Biochem. J., 54, 590 (1953).

5) Quartet splitting may be due to long range coupling with some proton. 


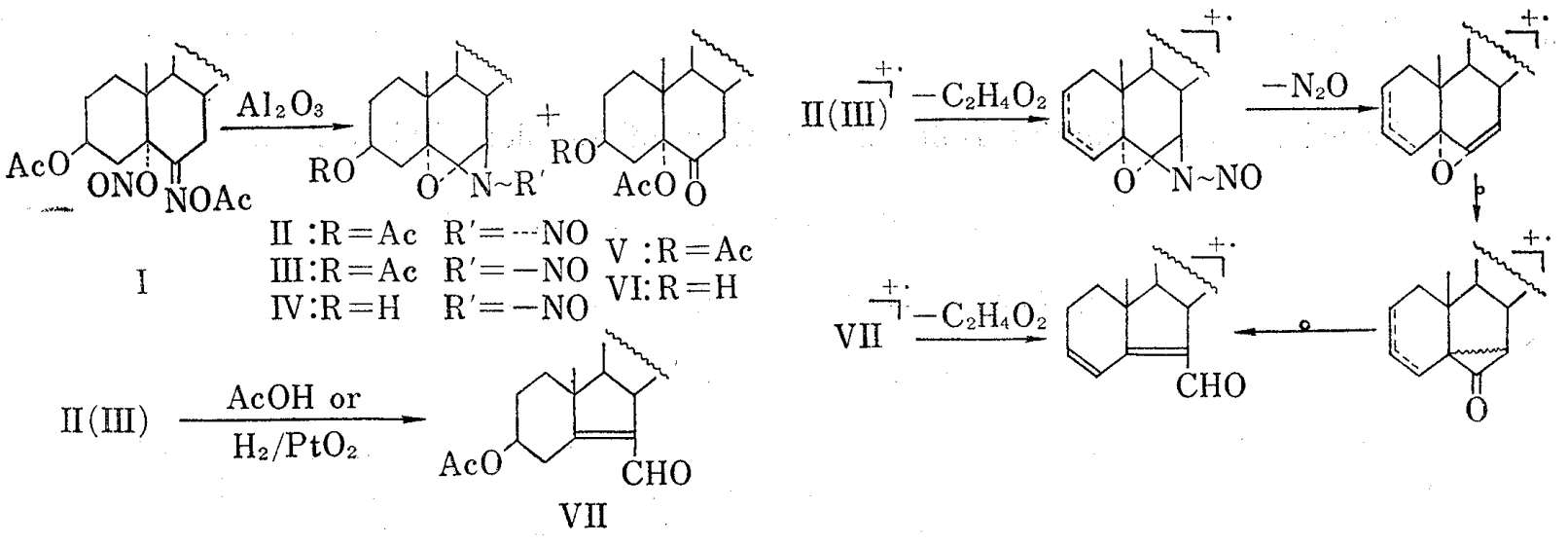

Chart 1

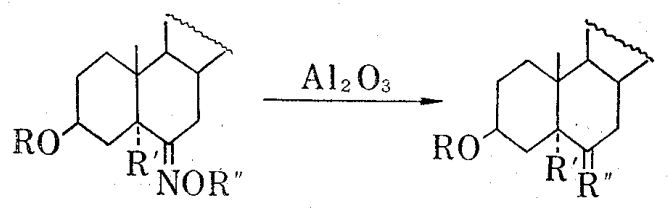

\begin{tabular}{|c|c|c|c|c|}
\hline & $\mathrm{R}^{\prime}$ & $\mathrm{R}^{\prime \prime}$ & $\mathrm{R}$ & $\mathrm{R}^{\prime}$ \\
\hline III : & $\mathrm{H}$ & $\mathrm{Ac}$ & IX : Ac & $\mathrm{H}$ \\
\hline $\mathrm{X}: \mathrm{H}$ & ONO & $\mathrm{H}$ & $\mathrm{XI}: \mathrm{H}$ & $\mathrm{OH}$ \\
\hline
\end{tabular}

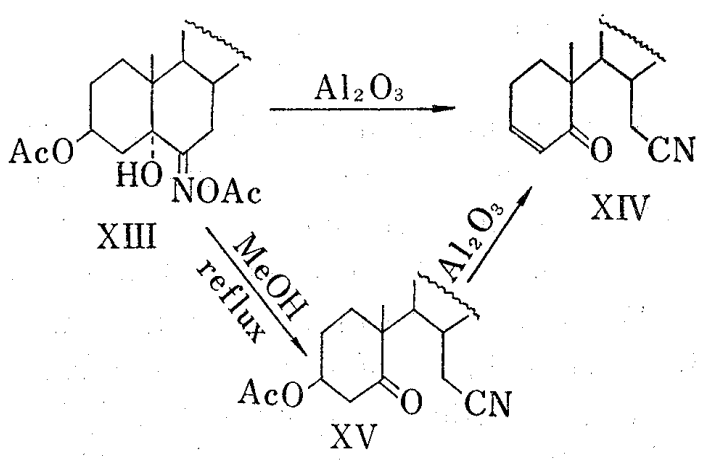

Chart 2

TABLE I. Partial Mass Spectra of II, III and VII $a$ )

\begin{tabular}{llrrr}
\hline \hline & \multicolumn{1}{c}{ Transition } & \multicolumn{2}{c}{ Relative intensity } \\
& m/e & II & III & VII $^{b)}$ \\
\hline 26 & $\mathrm{M}^{b} \mathrm{C}_{2} \mathrm{H}_{4} \mathrm{O}_{2}$ & 100 & 100 & \\
382 & $\mathrm{M}-\left(\mathrm{C}_{2} \mathrm{H}_{4} \mathrm{O}_{2}+\mathrm{N}_{2} \mathrm{O}\right)$ & 50 & 45 & 78 \\
367 & $\mathrm{M}-\left(\mathrm{C}_{2} \mathrm{H}_{4} \mathrm{O}_{2}+\mathrm{N}_{2} \mathrm{O}+\mathrm{Me}\right)$ & 21 & 12 & 20 \\
353 & $\mathrm{M}-\left(\mathrm{C}_{2} \mathrm{H}_{4} \mathrm{O}_{2}+\mathrm{N}_{2} \mathrm{O}+\mathrm{CHO}\right)$ & 59 & 40 & 88 \\
269 & $\mathrm{M}-\left(\mathrm{C}_{2} \mathrm{H}_{4} \mathrm{O}_{2}+\mathrm{N}_{2} \mathrm{O}+\mathrm{C}_{8} \mathrm{H}_{17}\right)$ & 20 & 9 & 19 \\
\hline
\end{tabular}

a) These compounds did not show the peaks due to the molecular ions.

b) The base peak corresponded to $m / e 18$.

III is an isomer of II from the IR, NMR and mass spectra. Treatment of III with acetic acid, also, afforded VII. On the basis of the chemical shift of $10 \beta$-Me (III: $\delta 1.17$ ), NO groups in II and III will be assigned anti and syn, respectively, to $10 \beta$-Me. IV was obtained during chromatographic purification of III. Its IR and NMR spectra show that IV is $3 \beta-\mathrm{OH}$ derivative of III resulted from hydrolysis of $3 \beta$-OAc groups.

In order to consider the formation pathways of II and III, chromatography of the relative compounds was examined under the same condition. 6-Acetoximino-3 $\beta$-acetoxy- $5 \alpha$-cholestane (VIII) and 6-hydroximinocholestane-3 $\beta, 5 \alpha$-diol 5 -nitrite (X) afforded an oxime (IX) and a diolone $(\mathrm{XI})$, respectively. These reactions are the simple hydrolyses of acetoximino, hydroximino, and nitrite groups. 6-Hydroximino- $3 \beta$-acetoxycholestan-5 $\alpha$-ol (XII) did not react on alumina. 6-Acetoximino-3 $\beta$-acetoxycholestan-5 $\alpha$-ol (XIII) afforded a syrupy compound (XIV), $\mathrm{C}_{27} \mathrm{H}_{43} \mathrm{ON}$, in a good yield. Its IR spectrum shows the absorptions at $2240(\mathrm{CN})$ and $1676 \mathrm{~cm}^{-1}(\mathrm{CO})$, and NMR spectrum $\left(\mathrm{CDCl}_{3}\right)$ shows the signals for two vinyl 
protons at $\delta 6.00 \mathrm{~d}(J=8)$ and $6.80 \mathrm{bd}(J=8)$. These spectral data suggest that XIV is 6cyano-5,6-secocholest-3-en-5-one. On the other hand, refluxing a solution of XIII in methanol quantitatively gave a cyanoketone $(\mathrm{XV}), \mathrm{C}_{29} \mathrm{H}_{47} \mathrm{O}_{3} \mathrm{~N}$, whose IR spectrum exhibited the absorptions at $2240(\mathrm{CN}), 1745(\mathrm{OAc})$, and $1710 \mathrm{~cm}^{-1}(\mathrm{CO})$, and NMR spectrum (100 MHz, $\left.\mathrm{CDCl}_{3}\right)$ had the signals at $\delta 5.42 \mathrm{bs}\left(W_{\mathrm{H}}=8,3 \alpha-\mathrm{H}\right)$ and $2.00 \mathrm{~s}(3 \beta$-OAc). These data are consistent with $3 \beta$-acetoxy-6-cyano-5,6-secocholestan-5-one' for $\mathrm{XV} . \mathrm{XV}$ was also converted quantitatively into XIV by treatment with alumina." It can be seen that an abnormal Beckmann rearrangement of XIII on alumina or in methanol is exclusively driven by $5 \alpha-\mathrm{OH}$ group.

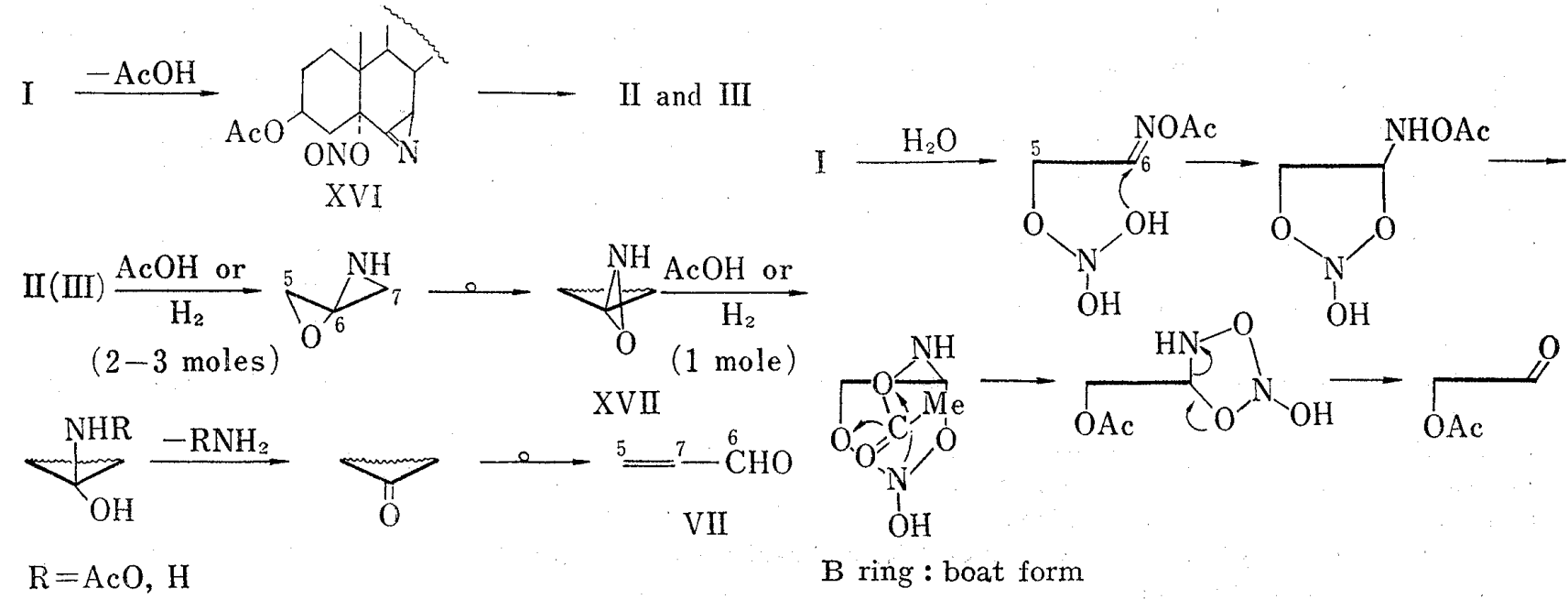

Chart 3

Chart 4

From above results, VIII, X, XII, and XIII-type compounds can be excluded from intermediates in the formation of II and III. As shown in Chart 3, I eliminates acetic acid to give an azirine (XVI) via the first step of the Neber rearrangement, ${ }^{8)}$ in which $5 \alpha$-ONO group adds to the double bond of the azirine group to afford II and III. The formation pathways of VII by acetic acid and catalytic reduction are depicted in Chart 3. The first step would be acetolysis or hydrogenolysis of the nitrite group to afford an aziridine which rearranges to a spiro-oxaziridine (XVII). After acetolysis or hydrogenolysis XVII would be converted into a cyclopropanone which rearranges to VII.

It seems that the acetyl groups in $5 \alpha-\mathrm{OAc}$ in $\mathrm{V}$ and VI migrate from $6=\mathrm{NOAc}$ group and VIII, X, XII, and XIII-type compounds are, also, not intermediates in the formation of V and VI. Since $5 \alpha$-ONO group was easily hydrolyzed $(\mathrm{X} \rightarrow \mathrm{XI})$, the first step would be hydration at the double bond of $5 \alpha$-ONO group and the successive steps are considered to be similar to that of the compounds containing $5 \alpha$-OAc group from I by catalytic reduction ${ }^{1)}$ (Chart 4).

\section{Experimental}

Melting points were determined on a micro hot-stage and were uncorrected. Ultraviolet (UV) spectra were measured with a Hitachi EPS-2U. IR spectra were measured with a JASCO IR-G in carbon tetrachloride: NMR spectra were taken on a Varian HA-100 and T-60. Mass spectra were taken on a JEOL's

6) E. Zbrial, G. Nestler, and K. Kischa, Tetrahedron, 26, 1427 (1970).

7) The chemical shift and half-height width of $3 \alpha-\mathrm{H}$ in $\mathrm{XV}$ represent the characteristics of an equatorial proton attached to acetoxy-substituted carbon in cyclohexane systems. Since a study of the solventinduced shift in the $100 \mathrm{MHz}$ NMR spectrum of XV leads to "axial" methyl group $\left(\delta_{\mathrm{CDCl}_{3}}-\delta_{\mathrm{C}_{6} \mathrm{D}_{8}}=0.18\right.$ ppm) at $\mathrm{C}-10$, it is considered that the $\mathrm{A}$ ring in $\mathrm{XV}$ does not exist in the chair form but in a flexible or twisted boat-like conformation. The facile elimination of acetic acid from the A ring in XV on alumina may be attributed to the location of the carbonyl group at $\beta$-position to acetoxyl group and the axiallike orientation of $3 \beta-\mathrm{OAc}$ group.

8) L.G. Donaruma and W.Z. Heldt, Organic Reactions, 11, 45 (1960). 
JMS-01SG. Exact mass measurements were performed by using the appropriate perfluorokrrosene peaks as refence masses. All spectra were determined at the lowest possible source temperature $\left(100\right.$ to $\left.160^{\circ}\right)$ using the direct inlet system with an electron energy of $75 \mathrm{eV}$.

Reaction of 6-Acetoximino-3 $\beta$-acetoxycholestan-5 $\boldsymbol{\alpha}$-ol Nitrite (I) on Alumina-A solution of I $(3.0 \mathrm{~g})$ in $n$-hexane-benzene $(1: 1)(10 \mathrm{ml})$ was remained on a column of neutral alumina (grade III) (150 g) for $48 \mathrm{hr}$. Elution with $n$-hexane-benzene (1:1) afforded $3 \beta$-acetoxy- $5 \alpha, 6 \alpha$-epoxy- $6 \beta, 7 \beta$-isonitrosoiminocholestane (II) $(384 \mathrm{mg})$ as colorless needles of $\mathrm{mp} 177-179^{\circ}$ from methanol. UV: $\lambda_{\max }^{\text {Etor }} 225(\varepsilon 6350)$ and $292 \mathrm{~m} \mu(\varepsilon$ 6770). Anal. Calcd. for $\mathrm{C}_{29} \mathrm{H}_{46} \mathrm{O}_{4} \mathrm{~N}_{2}: \mathrm{C}, 71.57 ; \mathrm{H}, 9.53 ; \mathrm{N}, 5.76$. Found: $\mathrm{C}, 71.23 ; \mathrm{H}, 9.59 ; \mathrm{N}, 5.64$. The next fraction gave crude III $(110 \mathrm{mg})$, whose re-chromatography gave III $(56 \mathrm{mg})$ as colorless needles of mp $140-142^{\circ}$ from methanol and IV $(37 \mathrm{mg})$ as colorless needles of $\mathrm{mp} 185-191^{\circ}$. III, IR: 1740 (OAc), 1705 and $1610 \mathrm{~cm}^{-1}(>\mathrm{N}-\mathrm{NO})$. NMR $\left(\mathrm{CCl}_{4}\right): \delta 4.53 \mathrm{~m}(3 \alpha-\mathrm{H}$ and $7 \alpha-\mathrm{H}), 3.07 \mathrm{q}(J=16$ and $4,4 \alpha-\mathrm{H}), 2.00 \mathrm{~s}(3 \beta-$ $\mathrm{OAc})$, and $1.17 \mathrm{~s}(10 \beta-\mathrm{Me})$. Anal. Calcd. for $\mathrm{C}_{29} \mathrm{H}_{46} \mathrm{O}_{4} \mathrm{~N}_{2}: \mathrm{C}, 71.57 ; \mathrm{H}, 9.53 ; \mathrm{N}, 5.76$. Found: C, 70.98; $\mathrm{H}, 9.53 ; \mathrm{N}, 5.80$. IV, IR: $3400(\mathrm{OH}), 1705$ and $1610 \mathrm{~cm}^{-1}(>\mathrm{N}-\mathrm{NO})$. NMR $\left(\mathrm{CDCl}_{3}\right): \delta 4.63 \mathrm{q}(J=8$ and $3,7 \alpha-\mathrm{H}), 3.60 \mathrm{~m}\left(\mathrm{~W}_{\mathrm{H}}=24,3 \alpha-\mathrm{H}\right), 3.00 \mathrm{q}(J=16$ and $4,4 \alpha-\mathrm{H})$, and $1.20 \mathrm{~s}(10 \beta-\mathrm{Me})$. Anal. Calcd. for $\mathrm{C}_{27} \mathrm{H}_{44^{-}}$ $\mathrm{O}_{3} \mathrm{~N}_{2}: \mathrm{C}, 72.93 ; \mathrm{H}, 9.97 ; \mathrm{N}, 6.30$. Found: $\mathrm{C}, 73.04 ; \mathrm{H}, 10.08 ; \mathrm{N}, 6.25$. Mass Spectrum: Calcd. for $\mathrm{C}_{27} \mathrm{H}_{44^{-}}$ $\mathrm{O}_{3} \mathrm{~N}_{2}$ : mol. wt., 444.335. Found: $\mathrm{M}^{+}, 444.332$. The following fraction, further, gave $3 \beta, 5 \alpha$-diacetoxycholestan-6-one (V) $(158 \mathrm{mg})$ as colorless needles of $\mathrm{mp} 175-178^{\circ}$ from methanol, which was identified with an authentic sample ${ }^{1)}$ by mixed melting point, and IR and NMR spectral comparison. The final fraction eluted with chloroform gave $5 \alpha$-acetoxycholestan-3 $\beta$-ol-6-one (VI) $(812 \mathrm{mg})$ as colorless needles of mp 181 $183^{\circ}$ from methanol, which was identified with an authentic sample1) by mixed melting point, and IR and NMR spectral comparison.

Reaction of 6-Acetoximino-3 $\beta$-acetoxy-5 $\alpha$-cholestane (VIII) on Alumina-A solution of VIIT (130 mg) in chloroform $(7 \mathrm{ml}$ ) was treated with neutral alumina (Grade III) $(7 \mathrm{~g})$ as described above. Elution with benzene-chloroform (1:1) gave 6-hydroximino-3 $\beta$-acetoxycholestane (IX) (92 mgr) as colorless needles of mp $198-200^{\circ}$ from methanol, which was identified with an authentic sample ${ }^{9}$ by mixed melting point, and IR and NMR spectral comparison.

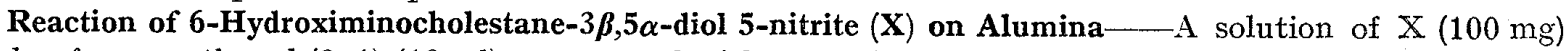
in chloroform-methanol $(9: 1)(10 \mathrm{ml})$ was treated with neutral alumina (Grade III) (6 g) as described above. Elution with chloroform-methanol gave $3 \beta, 5 \alpha$-dihydroxycholestan-6-one (XI) (41 mg) as colorless needles of $\mathrm{mp} 228-232^{\circ}$ from chloroform, which was identified with an authentic sample ${ }^{10}$ ) by mixed melting point, and IR and NMR spectral comparison.

6-Cyano-5,6-secocholest-3-en-5-one (XIV)—(1) A solution of 6-acetoxyimino-3 $\beta$-acetoxycholestan$5 \alpha$-ol (XIII) $(860 \mathrm{mg})$ in $n$-hexane-benzene $(1: 1)(2 \mathrm{ml})$ was treated with neutral alumina (Grade III) (45 g) as described above. Elution with $n$-hexane-benzene (1:1) gave XIV (554 mg) as a syrup. Mass Spectrum Calcd. for $\mathrm{C}_{27} \mathrm{H}_{43} \mathrm{ON}$ : mol. wt., 397.334. Found: $\mathrm{M}^{+}, 397.331$.

(2) A solution of $3 \beta$-acetoxy-6-cyano-5,6-secocholestan-5-one (XV) (143 mg) in $n$-hexane-benzene (1:1) $(0.7 \mathrm{ml})$ was treated with neutral alumina $(7 \mathrm{~g})$ as described above. Elution with $n$-hexane-benzene (1:1) gave a syrupy compound $(125 \mathrm{mg})$, which was identified as XIV by IR and NMR spectral comparison.

$3 \beta$-Acetoxy-6-cyano-5,6-secocholestan-5-one (XV)-A solution of XIII (213 mg) in methanol $(6 \mathrm{mI})$ was refluxed for $4 \mathrm{hr}$. After evaporation in vacuo, the residue was recrystallized from $n$-hexane to afford colorless needles $(184 \mathrm{mg})$ of mp 95-97 . Anal. Calcd. for $\mathrm{C}_{29} \mathrm{H}_{47} \mathrm{O}_{3} \mathrm{~N}: \mathrm{C}, 76.10 ; \mathrm{H}, 10.35 ; \mathrm{N}, 3.06$. Found: C, $75.87 ; \mathrm{H}, 10.25 ; \mathrm{N}, 2.92$.

3ß-Acetoxy-6-formyl-B-norcholest-5-ene (VII)_—(1) A solution of II (98 $\mathrm{mg})$ in acetic acid (16 ml) was allowed to stand for $24 \mathrm{hr}$ at room temperature. The reaction mixture was poured into ice-water and extracted with benzene. The benzene layer was washed with aq. $\mathrm{Na}_{2} \mathrm{CO}_{3}$ and water. The benzene residue afforded colorless needles $(87 \mathrm{mg})$ of $\mathrm{mp} 128-129^{\circ}$ from methanol. UV: $\lambda_{\max }^{\text {Etor }} 253.5 \mathrm{~m} \mu(\varepsilon 10400)$. Anal. Calcd. for $\mathrm{C}_{29} \mathrm{H}_{46} \mathrm{O}_{3}: \mathrm{C}, 78.68 ; \mathrm{H}, 10.47$. Found: $\mathrm{C}, 78.48 ; \mathrm{H}, 10.28$. Mass Spectrum Calcd. for $\mathrm{C}_{27} \mathrm{H}_{42} \mathrm{O}$ : mol. wt., 382.323. Found: $\mathrm{M}^{+}-\mathrm{C}_{2} \mathrm{H}_{4} \mathrm{O}_{2}, 382.325$. 2,4-Dinitrophenylhydrazone: $\mathrm{mp} 208-209^{\circ}$. UV: $\lambda_{\max }^{\mathrm{EtOH}}$ $384 \mathrm{~m} \mu\left(\varepsilon\right.$ 25,550). Anal. Calcd. for $\mathrm{C}_{35} \mathrm{H}_{50} \mathrm{O}_{6} \mathrm{~N}_{4}: \mathrm{C}, 67.50 ; \mathrm{H}, 8.09 ; \mathrm{N}, 9.00$. Found: C, 67.23; H, 8.13; $\mathrm{N}, 8.92$. It was identified with an authentic sample) by mixed melting point and UV spectral comparison.

(2) A solution of III $(38 \mathrm{mg})$ in acetic acid $(6 \mathrm{ml})$ was allowed to stand for 3 days at room temperature. Work-up afforded VII (17 mg), mp 128-129 , and 6-formyl-B-norcholesta-3,5-diene (12 mg), whose 2,4dinitrophenylhydrazone, $\mathrm{mp} 260-262^{\circ}$, was identified with an authentic sample ${ }^{4}$ by mixed melting point and UV spectral comparison.

(3) A solution of II $(500 \mathrm{mg})$ in benzene $(20 \mathrm{ml})$ and methanol $(30 \mathrm{ml})$ was hydrogenated over platinum black obtained from $\mathrm{PtO}_{2}(100 \mathrm{mg})$ at room temperature and $\mathrm{H}_{2}(100 \mathrm{ml})$ was absorbed during $2 \mathrm{hr}$. After filtration, the filtrate was evaporated in vacuo. The residue was recrystallized from methanol to give colorless needles of $\mathrm{mp} 128-129^{\circ}$.

9) J. Barnett, B.E. Dyman, and F. Smith, J. Chem. Soc., 1946, 528.

10) L.F. Fieser and S. Rajagopa, J. Am. Chem. Soc., 71, 3938 (1949). 